\title{
Effects of pentachlorophenol (PCP) on the oxygen consumption rate of the river puffer fish Takifugu obscurus
}

\author{
W. S. Kim ${ }^{1}$, J. K. Jeon ${ }^{1}$, S. H. Lee ${ }^{2}$, H. T. Huh ${ }^{1, *}$ \\ ${ }^{1}$ Marine Biotechnology Lab., and ${ }^{2}$ Chemical Oceanography Division, \\ Korea Ocean Research \& Development Institute, Ansan, PO Box 29, Seoul 425-600, Korea
}

\begin{abstract}
Laboratory bioassays were conducted to determine the effects of pentachlorophenol (PCP) on the oxygen consumption of the river puffer fish Takifugu obscurus. Oxygen consumption of 6 to 9 mo old puffer fish was measured with an automatic intermittent-flow-respirometer (AIFR). Oxygen consumption rate was significantly increased by exposing fish to concentrations of 50, 100, 200 and $500 \mathrm{ppb}$ PCP. Following exposure to 50 or $100 \mathrm{ppb}$ PCP, the instantaneous rate of oxygen consumption was considerably increased. T. obscurus exposed to $200 \mathrm{ppb}$ PCP, however, exhibited a breakdown in the biorhythm of oxygen consumption presumably due to a strong physiological stress caused by the higher PCP concentrations. River puffer fish exposed to $500 \mathrm{ppb}$ PCP died in $10 \mathrm{~h}$.
\end{abstract}

KEY WORDS: PCP. Oxygen consumption - River puffer fish Takifugu obscurus

\section{INTRODUCTION}

Pentachlorophenol (PCP) is a widely used biocide (Cirelli 1978), even though it is known to be highly toxic to most living organisms. Samis et al. (1993) reported that growth rate of bluegills Lepomis macrochirus was significantly reduced at a PCP concentration of $48 \mathrm{ppb}$. Its primary mode of action appears to be the uncoupling of mitochondrial oxidative phosphorylation at low concentrations (Bostrom \& Johansson 1972) and complete inhibition of the electron transport chain at higher concentrations (Desaiah 1978).

Toxic chemicals may cause damage to the gill membranes and affect the physiological functions of the fish in variety of ways (Jobling 1994). Toxic compounds are accumulated in animal organs, especially in the liver of fish, where accumulated concentrations can be more than 1000-fold higher than in the environment (Freitag et al. 1982, Gluth et al. 1985). Palmer (1995) stated that

·E-mail: hthuh@sari.kordi.re.kr one way to decipher the bio-physico-chemical linkage would be to test the effects of a variety of chemicals on organism biorhythms, i.e. how they alter their periods or phase. Despite the well-documented role of PCP in biochemical responses (Coglianese \& Jerry 1982, Yousri \& Hanke 1985, Castren \& Oikari 1987) and ecological processes (Whitney et al. 1981, Kierstead \& Baerlocher 1989, Freedman 1995), its effects on metabolic activities and biological rhythm of oxygen consumption of fish have not been well described.

The river puffer fish is endemic to Korean and Chinese waters (Chyung 1977), and known to spawn in spring in the rivers and migrate to the South China Sea in late autumn for wintering. This species is one of the most favored food fish and thus has been caught in significant quantities from most estuaries and freshwater habitats.

This paper deals with the direct effect of PCP on oxygen consumption of the river puffer fish measured by a specially designed automatic intermittent-flowrespirometer (AIFR). 


\section{MATERIALS AND METHODS}

Animals. The river puffer fish Takifugu obscurus used in the experiment were reared in a culture tank $(100$ l) for 6 to 9 mo after artificial insemination at the Korea Ocean Research and Development Institute (KORDI). The 20 fish [total length $=6.0 \pm 0.1 \mathrm{~cm}$ (mean \pm standard error, $x \pm \mathrm{SE}$ ), $1.05 \pm 0.04 \mathrm{~g}$ dry $\mathrm{wt}$ $(\mathrm{x} \pm \mathrm{SE})]$ were acclimatized to the experimental temperatures of $15^{\circ} \mathrm{C}$ over 4 wk.

Experimental design. For measurement of oxygen consumption rate in a control (no PCP) and at 4 different PCP concentrations, 4 Takifugu obscurus were put into a $1.4 \mathrm{l}$ experimental chamber at a time. The fish were starved during the experiments in order to exclude a rise in oxygen consumption due to feeding and digestion. The sea water ( 30.3 to $31.1 \%$ ) was filtered free of bacteria through sterile membrane filters (2 Sartorius capsule filters, input $0.2 \mu \mathrm{m}$ and output $0.07 \mu \mathrm{m}$, membrane pump, KNF, Neuberger, Germany) to reduce background oxygen consumption and to prevent the buildup of a microbial film in the apparatus (which was also thoroughly cleaned between experimental runs). Oxygen consumption rate was calculated from the changes in oxygen saturation level in the test chamber with time. The saturation concentration $K_{\mathrm{O}_{2}}\left(\mathrm{ml} \mathrm{l}^{-1}\right)$ was calculated for standard conditions (atmospheric pressure $P_{\text {atm }}=1 \mathrm{~atm}=1013 \mathrm{mbar}$ ) as a function of temperature and salinity using the formula of Weiss (1970):

$$
\begin{aligned}
\ln K_{\mathrm{O}_{2}}= & A_{1}+A_{2}(100 / T)+A_{3} \ln (T / 100)+A_{4}(T / 100)+ \\
& S\left[\left(B_{1}+B_{2}(T / 100)+B_{3}(T / 100)^{2}\right)\right]
\end{aligned}
$$

where $T$ is temperature (K) and $S$ is salinity (PSU) at the time of measurement, and $A$ and $B$ are the following constants: $A_{1}=-173.4292 ; A_{2}=249.6339$; $A_{3}=143.3483 ; A_{4}=-21.8492 ; B_{1}=-0.033096 ; B_{2}=$ $0.014259 ; B_{3}=-0.0017000$. To obtain the concentration in $\mathrm{mg}^{-1}$, the following conversion of gas volume $V_{\text {std }}$ under standard conditions into the gas volume $V_{R}$ under measured conditions was used:

$$
V_{\mathrm{R}}=V_{\text {std }}\left(1013 / P_{\mathrm{atm}}\right)(T / 273.15)
$$

with $T(K)$ and $P_{\text {atrm }}$ (mbar) being taken at the time of measurement (Mortimer 1983). Following this, $K_{\mathrm{O}_{2}}$ (mg $\left.\mathrm{l}^{-1}\right)$ was calculated (Forstner \& Gnaiger 1983):

$$
K_{\mathrm{O}_{2}}\left(\mathrm{mg} \mathrm{l}^{-1}\right)=K_{\mathrm{O}_{2}}\left(\mathrm{ml} \mathrm{l}^{-1}\right) \times 1.429
$$

The following points should be observed to obtain a better result when an AIFR is used: (1) accumulation of excretory products should be avoided; (2) measurements should be conducted over long periods of time; (3) the oxygen tension during measurements should be kept above $86 \%$; (4) human intervention and disturbances should be avoided.

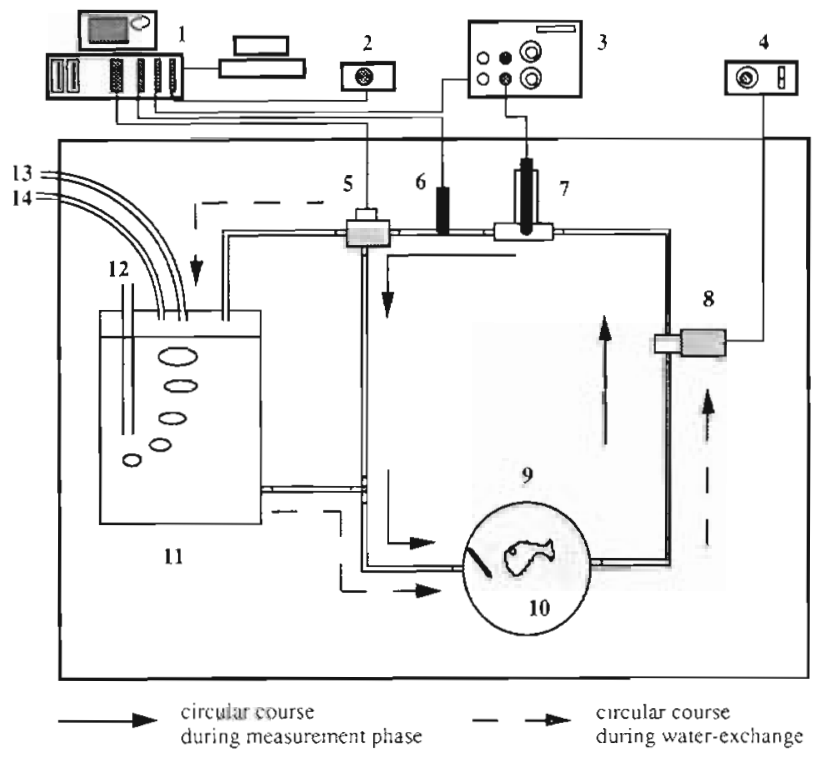

Fig. 1. Schematic (not to scale) of apparatus used to measure oxygen consumption in the river puffer fish Takifugu obscurus. 1: Computer for control and data storage; 2 : air pressure sensor; 3: picoammeter; 4: pump control; 5: 3-way valve; 6: temperature sensor 7 oxygen sensor; 8: toothed wheel pump; 9: chamber; 10: fish (test animal); 11: reservoir con-

tainer; 12: air supply; 13: air exhaust pipe; 14 : PCP input

With due regard to these points, the AIFR was specially designed (Fig. 1) by modifying that of Dorrien (1993) using much-improved software for the present study. Oxygen saturations were recorded at every second by the digital controlling unit through a picoammeter and the calculation of mean oxygen consumption displayed graphically every $90 \mathrm{~s}$. When the oxygen saturation dropped below the designed limit, the magnetic drive gear pump and 3-way magnetic valve (332F, Nortec, Germany) supplied the system with oxygen-saturated seawater until the selected oxygen saturation was reached. The magnetic drive gear pump (MS-Z, Ismatec SA, Switzerland) was installed horizontally and produced a water flow rate of about

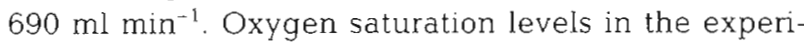
mental chamber were always maintained between $95 \%$ (highest) and $86 \%$ (lowest). The measuring system was installed in an experimental incubator (MLR350, REVCO, USA) with constant temperature of $15^{\circ} \mathrm{C}$ and in darkness. Salinity was measured with a salinometer (LF 320, WTW, Germany); water temperature and air pressure were continuously measured during the experiments using a thermometer (Pt-100, Farnell, Germany) and a barometer (Sensym-Hs 20. Farnell, Germany), respectively; and the oxygen probe (Eschweiler-15 $\mu \mathrm{PO}_{2}$, Germany) was calibrated before the experiment began. The whole experiment was controlled automatically by a computer program. After 
each experiment, the chamber was rinsed with oxygen-saturated water and the probe voltage examined to ascertain whether it had deviated from the gauge voltage at the beginning of the experiment. For reference, this voltage was subsequently tested between 6 and $24 \mathrm{~h}$ by measurement of the oxygen consumption in the chamber without any Takifugu obscurus present. No measurements were made while flushing the chamber with oxygen saturated seawater from a storage tank (10 l) to restore the upper oxygen saturation level to $95 \%$.

Pollutants. The PCP stock solutions were prepared using reagent grade PCP (P-1045, Sigma Chemical Co.) at concentrations of $50,100,200$, and $500 \mathrm{ppb}$. PCP solutions were injected through small holes cut on the cap of the reservoir container (see Fig. 1). Takifugu obscurus were exposed to PCP for ca $120 \mathrm{~h}$; this was found to be long enough to allow for the best results, yet short enough to minimize toxicant-produced mortality.

\section{RESULTS}

\section{Oxygen consumption rate of control group}

The oxygen consumption rate of the 4 river puffer fish not exposed to PCP varied from ca 0.23 to $1.82 \mathrm{ml}$
$\mathrm{O}_{2}(\mathrm{~g} \text { dry } \mathrm{wt})^{-1} \mathrm{~h}^{-1}$ with the mean consumption rate being $0.82 \pm 0.01(\mathrm{x} \pm \mathrm{SE}) \mathrm{ml} \mathrm{O}_{2}(\mathrm{~g} \text { dry } w t)^{-1} \mathrm{~h}^{-1}$. It showed a daily rhythm having 5 periods in about 120.3 h of experiment (Fig. 2). Peaks of oxygen consumption occurred at intervals of ca $24 \mathrm{~h}$ measured at around 08:00 h.

\section{Effects of PCP on oxygen consumption rate}

Exposure to $50 \mathrm{ppb}$ PCP. The instantaneous rate of oxygen consumption by river puffer fish exposed to $50 \mathrm{ppb}$ PCP increased for the first $20 \mathrm{~h}$ and then maintained the same rate throughout the test (Fig. 3). The mean oxygen consumption rate after exposure was $1.34 \mathrm{ml} \mathrm{O}_{2}$ (g dry $\left.w \mathrm{t}\right)^{-1} \mathrm{~h}^{-1}$ which is $32.7 \%$ greater than that before the exposure (Table 1).

Exposure to $100 \mathrm{ppb}$ PCP. Instantaneous rate of oxygen consumption of fish after exposure to $100 \mathrm{ppb}$ PCP was sharply increased and showed clear daily fluctuations (Fig. 4). The mean oxygen consumption rates before and after exposure to $100 \mathrm{ppb}$ averaged over the entire range of oxygen saturations were 1.07 and $1.67 \mathrm{ml}(\mathrm{g} \mathrm{dry} w \mathrm{t})^{-1} \mathrm{~h}^{-1}$, respectively. This shows that the fish at $100 \mathrm{ppb}$ PCP consumed about $56.1 \%$ more oxygen than the unexposed fish. Oxygen consumption rate of the fish at $100 \mathrm{ppb}$ PCP was about
Fig. 2. Takifugu obscurus. Time series of the oxygen consumption rate of 4 river puffer fish not exposed to PCP (control group). Fish (mean total length $5.9 \pm$ $0.1 \mathrm{~cm}, 4.3 \mathrm{~g}$ dry wt) were kept at $14.6^{\circ} \mathrm{C}$ and at oxygen saturation levels between 86.3 and $94.9 \%(\mathrm{SE}= \pm 0.04)$. (O) Mean oxygen consumption rate during $90 \mathrm{si}$ arrows indicate peaks of oxygen consumption at around 08:00 h

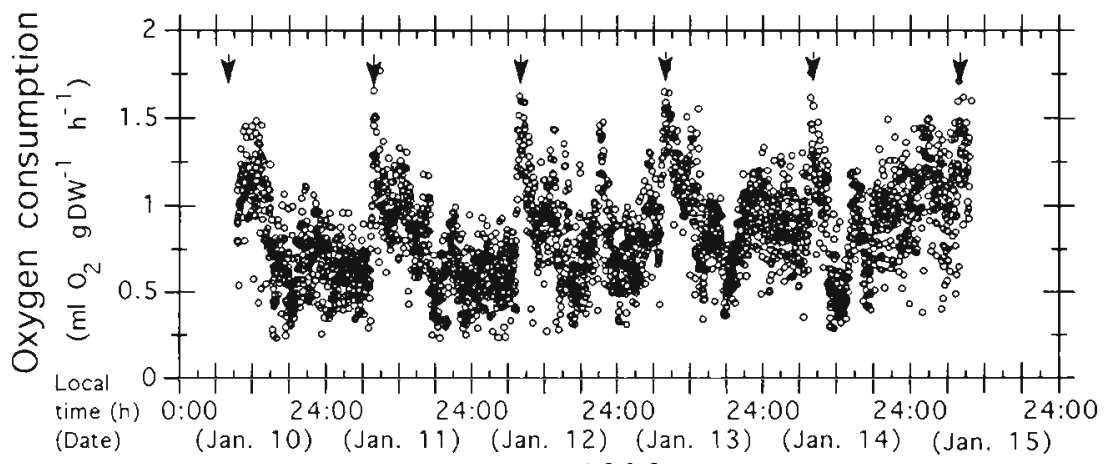

1996

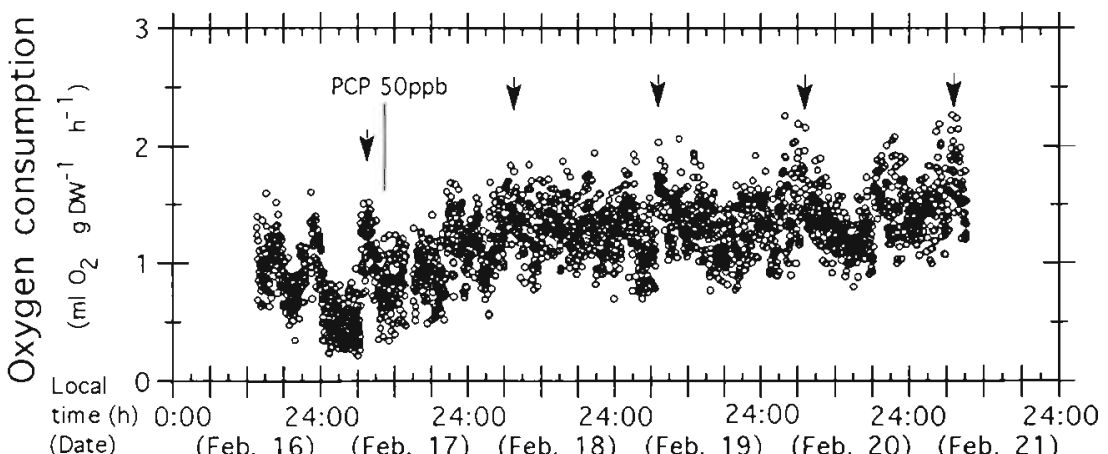

1996
(Date)

(Feb. 16)
Fig. 3. Takifugu obscurus. Patterns of the oxygen consumption rate of 4 river puffer fish (mean total length $6.1 \pm 0.1 \mathrm{~cm}, 4.3 \mathrm{~g}$ dry wt) before and after exposure to $50 \mathrm{ppb}$ PCP. Arrows indicate $\sim 08: 00 \mathrm{~h}$ 
Table 1. Takifugu obscurus. Rates of oxygen consumption by the nver puffer fish. Statistical values were computed for each batch from between 70 and 3185 measurements. Values are mean \pm standard error

\begin{tabular}{|c|c|c|c|c|c|}
\hline & Control & $50 \mathrm{ppb} \mathrm{PCP}$ & 100 ppb PCP & 200 ppb PCP & $500 \mathrm{ppb} P C P$ \\
\hline Number of indıviduals $(n)$ & 4 & 4 & 4 & 4 & 4 \\
\hline Mean total length $(\mathrm{cm})$ & $5.9 \pm 0.1$ & $6.1 \pm 0.1$ & $6.2 \pm 0.4$ & $5.6 \pm 0.2$ & $6.4 \pm 0.1$ \\
\hline Total dry weight $(g)$ & 4.3 & 4.3 & 4.3 & 4.1 & 4.3 \\
\hline Salinity $(\%)$ & 30.1 & 30.8 & 31.1 & 31.1 & 30.3 \\
\hline Flow rate $\left(\mathrm{ml} \mathrm{min}^{-1}\right)$ & 690 & 690 & 690 & 690 & 690 \\
\hline Temperature (C) & $14.6 \pm 0.004$ & $14.8 \pm 0.004$ & $14.7 \pm 0.005$ & $14.8 \pm 0.004$ & $14.6 \pm 0.009$ \\
\hline Level of oxygen saturation $\{\%\}$ & $\begin{array}{c}94.9-86.3 \\
( \pm 0.04)\end{array}$ & $\begin{array}{c}94.6-86.6 \\
( \pm 0.04)\end{array}$ & $\begin{array}{c}94.5-86.9 \\
( \pm 0.06)\end{array}$ & $\begin{array}{c}94.5-86.6 \\
( \pm 0.05)\end{array}$ & $\begin{array}{c}94.9-86.3 \\
( \pm 0.04)\end{array}$ \\
\hline Number of points measured (after exposure) & 3185 & 2048 & 886 & 1633 & 70 \\
\hline Duration (h) of the experiment after exposure to PCP & 120.3 & 93.1 & 74.6 & 74.6 & 7.0 \\
\hline Measurement interval (s) & 90 & 90 & 90 & 90 & 90 \\
\hline \multicolumn{6}{|l|}{ Mean oxygen consumption $\left(\mathrm{ml} \mathrm{O}_{2} \mathrm{~g} \mathrm{dry} \mathrm{wt}^{-1} \mathrm{~h}^{-1}\right)$} \\
\hline Before PCP exposure (A) & $0.82 \pm 0.01$ & $1.01 \pm 0.02$ & $1.07 \pm 0.01$ & $1.26 \pm 0.01$ & $0.95 \pm 0.02$ \\
\hline After PCP exposure $(B)$ & - & $1.34 \pm 0.01$ & $1.67 \pm 0.01$ & $2.03 \pm 0.01$ & $1.58 \pm 0.04$ \\
\hline Increase in rate of oxygen consumption $(\%)=(B-A) / A$ & - & 32.7 & 56.1 & 61.1 & 66.3 \\
\hline
\end{tabular}
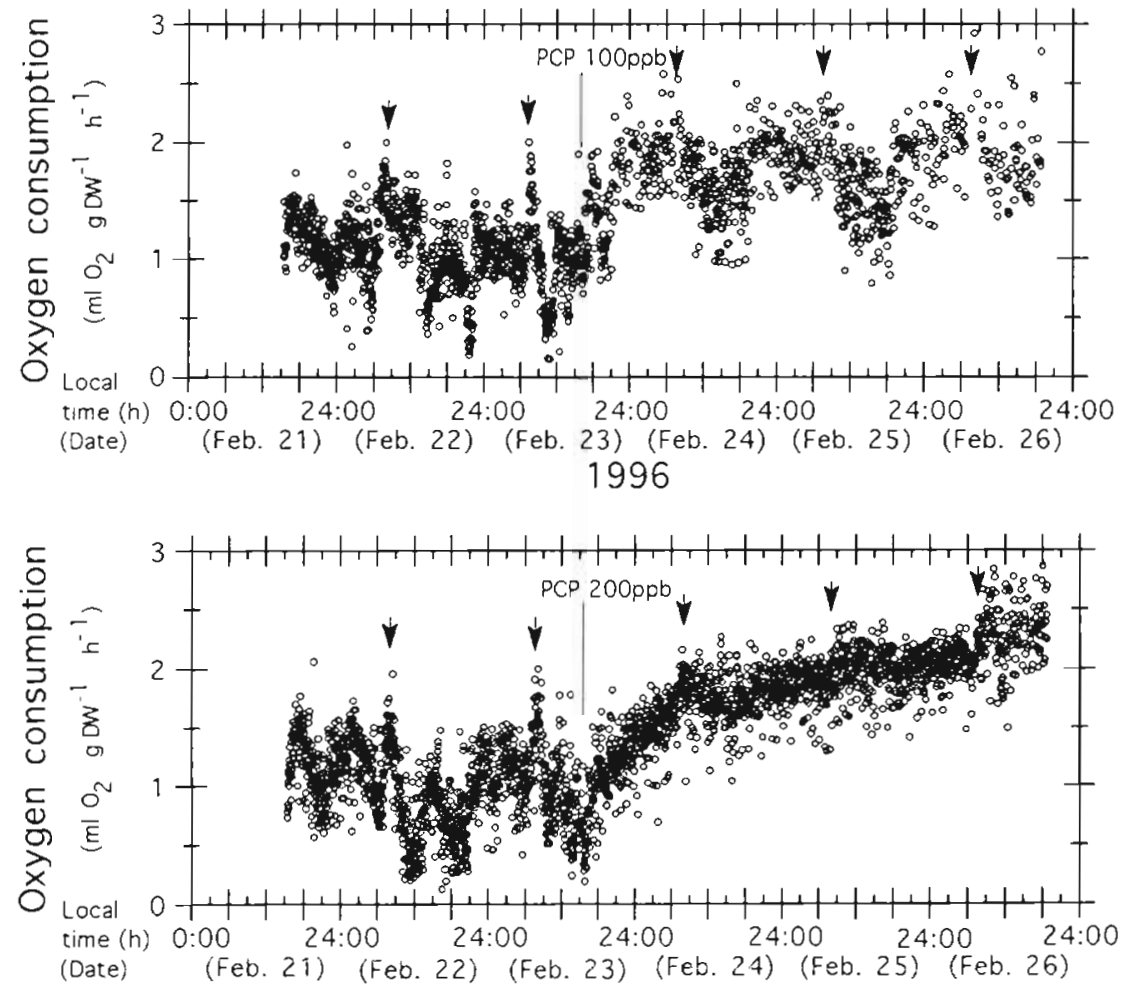

Fig. 4. Takifugu obscurus. Patterns of the oxygen consumption rate of 4 river puffer fish (mean total length $6.2 \pm 0.4 \mathrm{~cm}_{1} 4.3 \mathrm{~g}$ dry wt) before and after exposure to $100 \mathrm{ppb}$ PCP. Arrows indicate $\sim 08: 00 \mathrm{~h}$

Fig. 5. Takifugu obscurus. Patterns of the oxygen consumption rate of 4 river puffer fish (mean total length $5.6 \pm 0.2 \mathrm{~cm}, 4.1 \mathrm{~g}$ dry wt) before and after exposed to $200 \mathrm{pph}$ PCP. Arrows indicate $\sim 08: 00 \mathrm{~h}$ 1996

$24.6 \%$ greater compared to fish at $50 \mathrm{ppb} \mathrm{PCP}$ (Table 1).

Exposure to $200 \mathrm{ppb}$ PCP. The river puffer fish exposed to $200 \mathrm{ppb}$ PCP exhibited a pattern of oxygen consumption that was quite different from those exposed to 50 and $100 \mathrm{ppb}$ PCP. Both of the latter exhibited clear daily fluctuations (rhythms) of oxygen consumption (Figs. 3 \& 4), whereas the former showed no such a pattern (Fig. 5). Mean oxygen consumption rate of fish at
$200 \mathrm{ppb}$ PCP increased to $2.03 \mathrm{ml} \mathrm{O}_{2}(\mathrm{~g} \text { dry wt })^{-1} \mathrm{~h}^{-1}$ which is $61.1 \%$ higher than that for fish before exposure

Exposure to 500 ppb PCP. Prior to addition of PCP, the oxygen consumption rate was about $0.95 \mathrm{ml} \mathrm{O}_{2}$ (g dry $w t)^{-1} h^{-1}$ (Fig. 6, Period A). Following exposure to $500 \mathrm{ppb}$ PCP, it increased to $1.58 \mathrm{ml} \mathrm{O}_{2}(\mathrm{~g} \text { dry } w \mathrm{t})^{-1} \mathrm{~h}^{-1}$ (Fig. 6, Period B), about $66.3 \%$ higher than that for unexposed fish. All fish in the chamber died after $10 \mathrm{~h}$ exposure to 500 ppb PCP (Fig. 6, Period C). 
Fig. 6. Takifugu obscurus. Patterns of the oxygen consumption rate of 4 river puffer fish (mean total length $6.4 \pm 0.1 \mathrm{~cm}, 4.3 \mathrm{~g}$ dry $w t)$ before and after exposed to $500 \mathrm{ppb}$ PCP. Arrow indicates 08:00 h

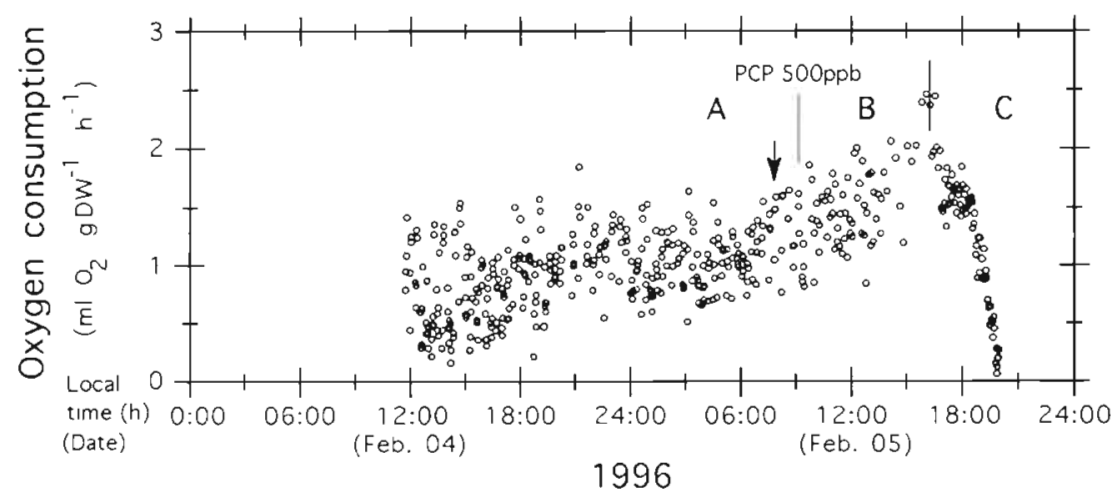

\section{DISCUSSION}

When fish are exposed to potential toxicants, the chemicals may directly affect metabolic reactions. Respiratory distress may arise as a result of either reduced oxygen diffusion over the gill membranes caused by an increase in the thickness of the mucous layer covering the secondary lamellae (Jobling 1994) or depleted haemoglobin content (Babu et al. 1985). Decrease in oxygen consumption rate with increasing time associated with the concentration of various pesticides in aquatic animals has been observed by a number of researchers (Babu et al. 1985, Muley \& Mane 1987. Reddy et al. 1987, Ritakumari \& Sreeletha 1987, Sambsiva-Rao et al. 1987, Mushithaq \& Nagarajan 1992, Ramarkrishnan \& Sivakumar 1993).

In river puffer fish, however, the oxygen consumption rate was increased when exposed to high concentrations of PCP up to $200 \mathrm{ppb}$. Even at $500 \mathrm{ppb}$ PCP it increased by $66.3 \%$ in the present study. Similar results were found from a freshwater fish Channa punctatus by Gopal et al. (1989) and Sastry et al. (1991). The opposite results for the oxygen consumption rates of fish obtained in the previous studies and those of the present one cannot be immediately explained. This could be partly due to the differences in methodologies used. In the present study, oxygen consumption was measured by a sensitive AIFR which provided a constant oxygen tension at levels above $86 \%$ saturation in the test chamber throughout the experiment. Oxygen measurements in other studies using conventional methods were made in a closed system which could not keep a constant oxygen saturation level in the experimental chamber. A drop in oxygen tension below a certain level in the test chamber would lower the metabolic activities of organisms.

A daily rhythmicity of respiratory activity was maintained in concentrations of PCP up to $100 \mathrm{ppb}$, but was completely dampened when the fish were exposed to 200 and 500 ppb PCP. It appeared that concentrations of PCP over $200 \mathrm{ppb}$ caused a strong physiological stress on the river puffer fish. Although the present study was not designed to determine 24 to $72 \mathrm{~h} \mathrm{LC}_{50}$ for PCP, it can be assumed from this experiment that the median lethal concentration for river puffer fish lies between 200 and $500 \mathrm{ppb}$ PCP, since there was no mortality for the fish at $200 \mathrm{ppb}$, while all fish died within $10 \mathrm{~h}$ at $500 \mathrm{ppb}$.

Throughout the experiments, the Takifugu obscurus were kept away from any external stimuli such as light, food, temperature, salinity or tide which may have affected their rhythmic activity. A pilot study with unexposed fish exhibited the distinctive peaks of the oxygen consumption at around 08:00 h, which can be considered to be a circadian rhythm with a period of ca $24 \mathrm{~h}$ (Fig. 2). Fanta et al. (1990) also found that oxygen consumption rate of an Antarctic fish, Notothenia neglecta, showed 1 peak at 08:00 h. More work is needed to understand the observed daily rhythm of oxygen consumption and its relationships with intrinsic or extrinsic factors. The rhythmicity of oxygen consumption in river puffer fish observed in this study under constant conditions appears to have profound implications for their physiological processes, especially with regard to the respiratory energy cost, and, therefore, could be a good reference in determining the oxygen consumption rate of other fish.

Acknowledgements. We thank Prof. T W Lee (Chungnam National University), Dr C. C. Shelley (Darwin Aquaculture Center, Australia) and Dr Sinjae Yoo (KORDI) for their helpful comments on an earlier draft of the manuscript. We also thank Mr H. S. Kim for providing the laboratory samples of river puffer fish. Financial support was provided by the Ministry of Science and Technology (MOST) of Korea under project PN00290.

\section{LITERATURE CITED}

Babu SBR, Jayasundaramma B, Ramamurthi R (1985) Physiology and recovery in juvenile Cyprinus carpio from methyl parathion induced stress. Matsya 11:97-101

Bostrom SL, Johansson RG (1972) Effects of pentachlorophenol on enzymes involved in energy metabolism in the liver of the eel. Comp Biochem Physiol 41B:359-369

Castren M, Oikari A (1987) Changes of the liver UDP-glucuronsyltransferase activity in trout (Salmo gairdneri Rich) 
acutely exposed to selected aquatic toxicants. Comp Biochem Physiol 86C:357-360

Chyung MK (1977) The fishes of Korea. Il-Ji Sa Press, Seoul, p 605-606

Cirelli DP (1978) Patterns of pentachlorophenol usage in the United States of America-an overview. In: Rao KR (ed) Pentachlorophenol. Plenum Press, New York, p 13-18

Coglianese MP, Jerry MN (1982) Brochemical responses of the blue crab, Callinectes sapidus, to pentachlorophenol. In: Vernberg WB, Calabrese A, Thurberg FP, Vernberg FJ (eds) Physiological mechanisms of marine pollutant toxicity. Academic Press, New York, p 127-143

Desaiah D (1978) Effects of pentachlorophenol on the ATPases in rat tissues. In: Rao KR (ed) Pentachlorophenol: chemistry pharmacology and environmental toxicology. Plenum Press, New York, p 277-283

Dorrien CF von (1993) Ecology and respiration of selected arctic benthic fish. Ber Polarforsch 125:1-99

Fanta EF, Lucchiari PH, Bacila M (1990) Circadian rhythm of oxygen consumption and oxygen levels in the muscle of Notothenia neglecta (Pisces, Teleostei). Comp Biochem Physiol 96C:151-155

Forstner H, Gnaiger E (1983) Polarographic oxygen sensors. Springer-Verlag, Berlin

Freedman B (1995) Environmental ecology: the ecological effects of pollution, disturbance, and other stresses. Academic Press, New York

Freitag D, Geyer H, Kraus A, Viswanathan R, Kotzias D, Attar A, Klein W, Korte F (1982) Ecotoxicological profile analysis. VII. Screening chemicals for their environmental behaviour by comparative evaluation. Ecotoxicol Environ Saf 6:60-81

Gluth G, Freitag D, Hanke W, Korte O (1985) Accumulation of pollutants in fish. Comp Biochem Physiol 81C:273-277

Gopal K, Ram MD, Anand M, Ray PK (1989) Toxicity and fate of lindane in fresh water fish Channa punctatus. Environ Ecol 7:571-576

Jobling M (1994) Fish bioenergetics. Chapman \& Hall, London

Kierstead WG, Baerlocher F (1989) Ecological effects of pen-

This article was submitted to the editor tachlorophenol on the brackishwater amphipod Gammarus tigrinus. Arch Hydrobiol 115: 149-156

Mortimer CE (1983) Chemie. Georg Thieme Verlag. Stuttgart

Muley DV. Mane UH. (1987) Pesticide induced alterations in the rate of oxygen uptake of freshwater gastropod, Viviparus bengalensis (Lamarck). J Anim Morphol Physiol 34:171-176

Mushithaq M. Nagarajan K (1992) Altered physiological parameters due to the pesticide ekalux in the fish Catla catla. Environ Ecol 10:445-447

Palmer JD (1995) The biological rhythm and clocks of intertidal animals. Oxford University Press, Oxford

Ramakrishnan R, Sivakumar AA (1993) Effect of quinolphos on the fish Oreochromis mossambicus. J Ecobiol 5:45-50

Reddy MS, Ghouselazam S, Babu TR, Rao KVR (1987) Changes in respiratory potentials of the penaid prawn Metapenaeus monoceros exposed to phosphamidon, DDT and fenvalerate. Environ Biol 5: 643-650

Ritakumari SD, Sreeletha KS (1987) Respiratory metabolism in Etroplus maculatus (Bloch) under estuarine conditions and pesticide stress. J Mar Biol Assoc India 29:226-231

Sambasiva-Rao K, Nagabhushanam R, Sarojini R (1987) Effect of dimecron on the oxygen consumption of the marine edible crab Scylla serrata. Environ Ecol 5:416-418

Samis AJW, Colgan PW, Johansen PH (1993) Pentachlorophenol and reduced food intake of bluegill. Trans Am Fish Soc 122:1156-1160

Sastry KV, Samuel M, Shukla V (1991) Metabolic alterations produced by the organochlorine pesticide aldrin in the freshwater fish Channa punctatus. In: Assoc Aquaculturalists Proceedings of the National Symposium on New Horizons in Freshwater Aquaculture, 23-25 January, 1991. ICAR-CIFA, India, p 179-181

Weiss RF (1970) The solubility of nitrogen, oxygen, and argon in water and seawater. Deep Sea Res 17:721-735

Whitney FA, Perry K, Philpott C, Ramey A, Wong CS (1981) Pentachlorophenol in a pelagic marine ecosystem: effects on the ecosystem. Pac Mar Sci Rep 81-3:32

Yousri R, Hanke W (1985) The effects of pentachlorophenol, phenol and other pollutants on the live of carp (Cyprinus carpio L.). Comp Biochem Physiol 82C:283-290

Manuscript first received: May 20, 1996

Revised version accepted: September 19, 1996 